\title{
LEON EDEL: LA NUEVA BIOGRAFÍA LITERARIA
}

María Antonia Álvarez

$U N E D$

Biografia quiere decir «escribir la vida», quizá para preservarla de la muerte; esto es, el biógrafo piensa que la lengua es capaz de recrear y perpetuar la vida, siendo su principal deseo sustituir por palabras una vida real. En Roma, a la muerte de sus hombres célebres, se escribía la laudatio o elogio fúnebre, y este modelo se transmitió a través de los siglos por la enseñanza de la Iglesia. En la misma época también existía en la literatura laica un paralelo a la oración fúnebre, que se acostumbraba a colocar al comienzo de la edición póstuma de las obras de un autor conocido, redactado normalmente por un familiar o discípulo del difunto. La vida de los héroes se narraba tal y como se había desarrollado, comenzando por el nacimiento y finalizando con la muerte, siendo su objetivo menos el de narrar los hechos que el de ilustrar unas ideas, incluir una digresión o dar una vuelta atrás y trazar un panorama histórico; el orden cronológico se veía interrumpido por un objetivo temático o didáctico.

El término «biografia», de uso tan corriente en nuestros días, tiene una antigüedad aproximada de dos siglos y medio. No se conoce su uso antes del siglo XVIII y el primer diccionario que lo admitió, según Georges May', fue el Trévoux en 1721; es decir, la denominación es en muchos siglos posterior a la existencia de verdaderas biografias, ya que Plutarco - hacia la mitad del siglo I de nuestra era-puede considerarse el primer biógrafo. En todo caso, el ejemplo más antiguo de la expresión «biography» aparece en un escrito de Dryden sobre Plutarco, de 1683.

' Georges May, L'autobiographie. Paris, Presses Universitaires de France, 1979, p. 184. 
En los Estados Unidos, después del período colonial, la importancia de lo individual dio lugar a que se empezaran a ocupar de la divulgación de las vidas de los hombres y mujeres notables, comenzando por los padres fundadores, principalmente como ejemplos a imitar.

$E$ linterés por la vida personal y la privada, por la vida íntima del hombre, comenzó en las letras inglesas en el siglo XVIII, como presagio del romanticismo. Primero apareció el poeta y más tarde la curiosidad por la vida del poeta. Si esta curiosidad o conciencia biográfica hubiera existido antes, no tendríamos que tratar ahora de recomponer las vidas de artistas como Chaucer o Shakespeare con los pocos vestigios que poseemos.

En cuanto a la forma, el lector puede sentir curiosidad por conocer el proceso de creación de una novela, pero nunca el de una biografia. Simplemente le preocupan los hechos que se describen, sin cuestionarse que ha existido un acto de composición. Cree que las biografias son fotografias, documentación y por esta razón hay pocos tratados sobre «the writting of lives».

Las bases para la fundación de la nueva biografia se establecieron durante la década de 1920, bajo la influencia beneficiosa de Strachey, a la que se unieron otros escritores como Harold Nicolson y André Maurois; el mismo Strachey, junto con Virginia Woolf, así como los discípulos que formaban el grupo más joven, lord David Cecil y Philip Cuedalla, entre otros ${ }^{2}$.

Nicolson, a pesar suyo, veía la autobiografia como condenada a convertirse en una obra científica; Maurois, por el contrario, consideraba que sólo podía ser un arte y debería aceptarse como tal.

Para Virginia Woolf no era ni ciencia ni arte, sino una especie de trabajo artesanal superior.

El tiempo ha demostrado que las previsiones de Nicolson no tenían fundamento, a pesar de que hayan aparecido biografias especializadas. Los biógrafos han continuado escribiendo, como propugnaba André Maurois, con la certeza de que el hombre es versátil y mientras su cerebro, su sistema nervioso y el resto de las condiciones humanas desafien a la mecanización, la biografia no puede llamarse científica.

Pero no hay razón para que no aspire a disponer de ciertos métodos científicos y a utilizar ayudas tecnólogicas. La cuestión está en cómo usar los conocimientos que sean aprovechables, en vez de argumentar sobre la polémica arte versus ciencia. La biografia es un arte cuando la obra está ya compuesta, cuando están ya unidos todos sus puntos y se le ha dado estructura, forma y estilo narrativo. $Y$ es meramente documental en la fase anterior, antes de componerla, cuando todo el material está reunido por

${ }^{2}$ Leon Edel, Writing Lives: Principia Biographica. New York \& London, W. W. Norton \& Company, 1984, p. 37. 
orden cronológico, sin establecer una teoría especial de selección ni un código de relevancia.

La biografia no es sólo un proceso intelectual, tiene que tener en cuenta las emociones, descubrir el contenido vivencial de su material y si desprecia la psicología moderna y sus descubrimientos, desaprovecha una rama completa de estudio e iluminación:

... psychology alone can help turn the baser metals of fact, the crude verbosity of documents, into the fold of human personality.

En realidad, la biografía toma tres postulados del psicoanálisis, según Leon $\mathrm{Edel}^{4}$ :

- Primero, la existencia de lo inconsciente en la motivación y el comportamiento humano: en los sueños, las imaginaciones y los pensamientos.

- Segundo, dentro de lo inconsciente existen ciertos sentimientos y estados de ánimo contenidos, que a veces emergen a la superficie en las formas creadas inconscientemente por la literatura.

- Tercero, por el proceso de inducción, esto es, al examinar la representación mental en palabras de las cosas ocultas a los sentidos, podemos descubrir intenciones y significados más profundos, valiosos para el biógrafo y para el crítico.

El arte es el resultado no de la calma y la tranquilidad, por mucha calma que el artista pueda experimentar en el acto de escribir, sino de la tensión y la pasión, de un estado de desequilibrio en el ser del artista. Y el psicoanalista, leyendo el boceto de la obra, puede intentar explicar cualquier error que exista en la mente del artista o en su salud psíquica. El biógrafo, leyendo el mismo boceto en el amplísimo cuadro de la condición humana, trata de mostrar cómo se convierten en positivos los aspectos negativos:

3bid., p. 38

4 Ibid., p. 148. 
how Proust translated his allergies and his withdrawal from the pain of experience, into the whole world of Combray, capturing in language the very essences which seemed illusory and evanescent in his consciousness; how Virginia Woolf, on the margin of her melancholy, pinned the feeling of the moment to the printed page as the hunter of butterflies pins his diaphanous and fluttering prize to his; and how James Joyce, visioning himself as Daedalus soaring over a world he had mastered, created a language for it in the word-salads of Finnegans Wake... These are triumphs of art over neurosis, and of literature over lifes.

Toda biografia es, en resumen, una reproyección en palabras, dentro de la forma literaria o de una especie de forma semicientífica o histórica, de materiales inertes recopilados por la mente del historiador o del biógrafo, que se convierte en la mente informadora. Sólo puede presentar los hechos desnudos, tal y como él los ha comprendido, pero dentro de una narrativa fluida que despierte el interés del lector ${ }^{6}$.

Entre las diferencias fundamentales en el género autobiográfico está el papel de la muerte. Las autobiografias no finalizan con la muerte del personaje: la esencia de cualquier autobiografia es que jamás puede llegar hasta el fin, que nunca puede decir la última palabra, como hace el biógrafo oficial ${ }^{7}$. Si uno de los móviles fundamentales del escritor es triunfar sobre la muerte, nunca llega a conocer si conseguirá alcanzar esta meta. Por el contrario, el biógrafo, desde el momento en que comienza a escribir, sabe que la memoria de su personaje ya se ha perpetuado más allá de la muerte. La ausencia de la muerte en la narración es una de las condiciones inherentes a la autobiografia 8 .

Otra diferencia importante es el papel de la memoria. Los materiales de que se sirve el biógrafo son, al igual que los del historiador, exteriores a él y puede distanciarse de ellos para someterlos a una crítica objetiva. Por el contrario, la autobiografia trabaja con materiales subjetivos, los propios recuerdos. Puede basar su obra en documentos ajenos a él, como son las cartas, e interpretarlas antes de incluirlas en su obra. En el caso de Henry James, al citar las cartas de su padre y de su hermano William, las revisaba libremente, como si sus textos necesitaran el mismo retoque dado a sus propias obras en la New York Edition. Cuando protestó su sobrino por la violación del lenguaje de su padre, le contestó que habia hecho tan sólo

\footnotetext{
Ibid., pp. 150-1.

Ibid., p. 43.

Georges May, op. cit., p. 192.

${ }^{8}$ Ibid., p. 193.
} 
... tiny amendments in order of words, degrees of emphasis, etc., to the end that he should be more easily and engagingly readable and thereby more tasted and liked from the moment there was no excess of these attentions and no violence done to his real identity".

Y mientras declaraba que sólo retocaba la forma, sutilmente alteraba el contenido también. Tenía el propósito de escribir la historia familiar de forma artística y, como la vida en su estado real era muy poco artística, unió dos viajes a Europa en uno sólo, e hizo que su padre escribiera una carta a Emerson en un lenguaje menos dubitativo que el original.

El tercer elemento que diferencia el género autobiográfico del biográfico es el orden de presentación. El primero procede remontando el curso del tiempo, partiendo del presente de la narración para alcanzar el pasado de la experiencia, objeto de su obra; el segundo también escribe en el presente, pero cuando habla de la infancia de un personaje, lo conoce por la documentación, no por la experiencia.

El escritor percibe su vida como compuesta de estratos de recuerdos entre los cuales el más elevado, el que está en la superficie, es el último, el que limita con el presente. La vida que ha de construir el biógrafo basándose en la documentación que posee consta de episodios dispuestos cronológicamente en sentido inverso, del nacimiento a la muerte; su personaje se construye envejeciendo, en tanto que, para el autobiógrafo, la vejez -experiencia vivida-, lejos de ser un principio de construcción, conduce inevitablemente a la muerte ${ }^{10}$.

En su ensayo Literary Biography", Leon Edel describe la biografia literaria moderna como

... a delicate and humane process of great complexity, as complex as life itself, involving wide-ranging curiosity and search, critical analysis, psychological insight and a quality of sympathy between biographer and subject between the hunter and the hunted all in the interest of truth, truth of life and of experience'?

Los cinco tomos que dedicó a la vida de Henry James, a pesar de las

${ }^{9}$ Leon Edel, Henry James: The Conquest of London (1970-81). Philadelphia, J. B. Lippincott Company, 1969, pp. 345-7.

in Ibid., p. 198.

" Leon Edel, Literary Biography. The Alexander Lecturer 1955-6. London, Rupert HartDavis, 1957, p. 102.

Ibid., p. 103. 
críticas en contra, según Dennis W. Petrie ${ }^{13}$, reflejan su plena valoración y comprensión del personaje, aunque el punto de vista predominante, la última mirada antes de la del lector, sea la suya. No quiere esto decir que manipule el tema, simplemente saca el mejor partido de las realidades prácticas y de las posibilidades estéticas de su larga conexión con James. Y añade:

If in the making of literary biographies as in the making of all works of literature form should follow function, critics of the Edel's biography would do well to realize that the criticism of this type of writing should also follow function should consider first the literary biographer's aim ${ }^{14}$.

Esta misma afirmación la hace Henry James en The Art of Fiction: «We must grant the artist his subject, his idea, his donée; our criticism is applied only to what he makes of it» ${ }^{15}$. Aplicada a la biografia literaria, la frase de James quiere decir que no sólo puede el biógrafo elegir su propio tema, sino también su propio acercamiento.

En el ensayo que escribió James en 1899 sobre George Sand, que Edel considera como punto de partida para la posterior biografia sobre el escultor William Wetmore Story, sugiere que quizá el artista, el tema,

should organize the game of biography on his own terms, rather than leave it to the terms of the biographer... The thing was indeed to burn papers, keep the secrets, challenge the biographer to dig harder for his facts, demand of him a genuine effort of inquiry and research ${ }^{16}$.

$Y$, realmente, esto fue lo que hizo Henry James con su biógrafo Leon Edel, hacerle trabajar de manera incansable para conseguir el material histórico relativo a su vida, por lo que no debe escatimarse el mérito del logro conseguido; la gran verdad de James es, en el fondo, «the aesthetic truth of Edel's articulated vision of someone who lived and wrote literature ${ }^{17}$, y lo que el lector observa en primer lugar es la criatura de la imaginación de Edel.

"Dannis W. Petrie, Ultimately Fiction: Design in Modern American Literary Biography. Indiana, Purdue University Press, 1981, p. 161.

14 Ibid., p. 147.

is Ibid.

16 Ibid., p. 162.

${ }^{17}$ Ibíd., p. 163. 
El mismo Leon Edel, en el volumen segundo de su biografía de James ${ }^{18}$, define el tipo de biografia que ha querido escribir. Afirma que en el hilado de los cuentos, en el uso de las palabras, en el desarrollo de un estilo, el escritor dibuja su ser característico, así como su genio; su trabajo, al final, se convierte en una especie de suprema biografia. Esa es la biografia que Edel ha tratado de leer consultando constantemente las columnas paralelas de las novelas, cuentos, crítica y fragmentos fugitivos, así como los documentos conservados de forma fortuita - aunque abundantemente--, nombres, lugares, fechas, relaciones personales, etc. Gracias a todo ello, ha ido encontrando imágenes de la figura perdida, del escritor en el punto medio de su carrera literaria, que se hallaba en plena posesión de su creatividad y buscaba la saturación de la experiencia. Cree que si se examina este material con respeto para aceptar la evidencia y las ambigüedades de la existencia, se llega a un Henry James mucho más consistente que la figura desdibujada de la leyenda.

En el volumen siguiente, The Treacherous Years, habla de su método biográfico, dado que parece que han preocupado algunas de sus críticas, principalmente en el mundo académico. Confiesa que ha aceptado el axioma de la psicología moderna:

... that there is sequence and consistency in the stuff of man's imagination; that an artist's work is less accidental than it has seemed... Biography has for too long occupied itself with the irrelevancies of daily life and overlooked the essential keys to character and personality: I refer to the ways in which an artist fashions the myth by which he lives... What is characteristic of emotional life and the way in which the emotions dictate -other elements and mysterious forces aiding - the exercises of the demonstrative and symbol-making imagination'.

Ya centrándose más directamente en el tema de su biografia de Henry James, dice que un escritor de novelas y cuentos, al tiempo que crea sus obras, nos va explicando parábolas personales de sí mismo y nos deja entrar en el secreto de su vida. La búsqueda de ese secreto es lo que Edel considera la verdadera finalidad de la biografia literaria, ya que en el caso de James

$\ldots$ in some strange way his writing of his late novels was a reliving of his

\footnotetext{
${ }^{18}$ Leon Edel, Henry James: The Conquest of London (1870-81). Ed. cit., p. 16.

${ }^{14}$ Leon Edel, Henry James: The Treacherous Years (1895-1901). Philadelphia, J. B. Lippincott Company, 1969, p. 16.
} 
earlier life; as if in middle age he had to reexamine, to try again, old artistic experiences, and test them in his maturity ${ }^{20}$.

Es decir, la biografia es para Leon Edel el arte del retrato humano en palabras, arte que es noble y emprendedor ${ }^{21}$.

En el último ensayo aparecido de Leon Edel, Writing Lives Principia Biographica, comienza diciendo que la biografia

attempts to preserve what it can of human greatness or humbleness; to describe a pilgrimage from childhood to maturity and finally to the grave, and in his process the labors, errors, passions and actions that lead to accomplishment ${ }^{22}$.

Para él, el escrito biográfico es una rama de la historia, íntimamente relacionada con ella, ya que una biografia sólo será completa si revela lo individual dentro del marco histórico, la colectividad y el complejo social.

Cree que el punto básico de la obra biográfica es la relación del autor con el personaje sobre el que escribe. Si lo idealiza, no podrá ver claramente el significado de los materiales que utiliza. La creatividad del biógrafo reside en el arte de la narración y no en el contenido de la historia, pues ésta ya existía antes de comenzar a escribir. No está de acuerdo con la opinión de algunos críticos en cuanto a que las biografias son una forma de ficción: el novelista sabe todo sobre el héroe o la heroina, sus personajes los ha inventado él y puede hacer lo que desee con ellos, es omnisciente. Por el contrario, el biógrafo nunca lo es, escribe sobre un personaje con unos documentos que existen y que le son dados, no puede alterarlos, pues alterar supone desfigurar. El biógrafo podrá analizar los hábitos y las características de sus personajes, estudiar su psicología, pero lo hace sobre personas que han existido $\mathrm{y}$, en muchos casos, eran ya famosas antes de aparecer en sus páginas.

Añade que toda biografía tiene en común su preocupación por captar lo auténtico de una vida y la experiencia, y si admitimos que el poeta es el poema, el novelista la novela y el dramaturgo el drama, también habremos de admitir que el biógrafo, si es un artista, se encarna en la biografia; no

20 Leon Edel, Henry James: The Master (1901-16). Philadelphia, J. B. Lipincott Company, 1972, p. 28.

2" Leon Edel, "The Figure in the Carpet", Telling Lives: The Biographer's Act. Ed. Marc Pachter. University of Pennsylvania Press, 1981, p. 20.

"2 Leon Edel, Writing Lives: Principia Biographica. Ed. cit., pp. 13-17. 
es anónimo, está presente en su obra, al igual que el pintor está presente en el retrato, para darla fuerza y sentimiento ${ }^{23}$.

Los cuatro principia biographica que presenta Leon Edel pueden resumirse del siguiente modo:

Primero, el biógrafo tiene que familiarizarse con la forma en que el hombre sueña, piensa y usa su fantasía. Esto no quiere decir que tenga que someter a su personaje a un psicoanálisis, pues no se trata de un paciente que necesite terapia, pero si se ha de buscar métodos analíticos aplicables a la biografia con los que utilizará las revelaciones que se contienen en la imaginación, el pensamiento y los sueños de su personaje. El acercamiento analítico es el que nos permite observar, a través del raciocinio, las actitudes, las ilusiones y las decepciones de los personajes: las manifestaciones del subconsciente al proyectarse en formas conscientes de acción, según el camino que el personaje haya elegido en su vida (incluso ya es reveladora la mera elección de ese camino). Este tipo de análisis no se aprende leyendo un libro de Freud, de Jung o de un psicoanalista moderno. Lo que sí es imprescindible es que el biógrafo aprenda a conocer su propia imaginación, a fin de no confundirla con la de su héroe.

Segundo, los biógrafos tienen que luchar constantemente para que el tema no les domine, no encariñarse demasiado con él, y el secreto de esta lucha está en convertirse en un observador-partícipe. Ser un buen biógrafo implica un grado de compromiso, si se quiere que la obra no carezca de emoción, pero, al mismo tiempo, se ha de dominar el tema de tal forma que pueda distanciarse de él: que tenga emoción no implica que haya identificación; una admiración o un cariño excesivos no dan como resultado una buena biografia, y menos aún el odio. Este problema de la identificación es básico en la biografía moderna, y explica muchos de los más serios fracasos.

Tercero, un biógrafo tiene que analizar los materiales para descubrir la clave de las verdades más profundas de su tema, la clave de la "mitología" del individuo. Estas claves pertenecen a las bases esenciales del comportamiento humano - ampliamente exploradas por la psicología moderna- y hay que estudiarlas asiduamente. A esto se refiere Edel cuando alude a la búsqueda constante de "the figure under the carpet», pues si estudiamos primero la figura en la alfombra,

Ibid., p. 34 . 
- that is the patterns and modes of a man's works, in literature, in politics, in most of his endeavors - we are able then to grasp what lies on the underside of the given tapestry. The public façade is the mask behind which a private mythology is hidden - the private dreams of the self. In seeking this mythology we use inductive methods as boldly as a detective uses deductive. The ways in which men and women handle their lives, the forms they give to their acts of living, their particular forms of sexual politics for example, their handling of human relations, their ways of wooing the world or disdaining it - all this is germane to biography, it is the very heart of a biography ${ }^{24}$.

Aunque un artista conozca la anatomía que hay debajo del traje, eso no es lo que pinta en el cuadro. La figura que aparece en el lienzo es la misma figura que aparece ante el mundo. Por tanto, el biógrafo debe estudiar a su personaje no como si se tratara de un objeto guardado en un cajón del archivador, sino como lo que este objeto representa: la imagen de una figura noble o perversa y, si se tratara de la segunda, hay que aceptarla en su perversión al igual que aceptamos la nobleza. Las claves mitológicas nos ayudan a guiarnos a través del laberinto que suponen los archivos modernos, sin olvidar que mientras la configuración mitológica está más o menos determinada, hay casos en los que podemos toparnos con el desarrollo o el cambio del yo.

Cuarto, cada vida adopta su propia forma y el biógrafo debe encontrar la forma literaria única e ideal que habrá de expresarla. Una biografia no necesita ser estrictamente cronológica en cuanto a su estructura, como lo es el calendario o la agenda, ya que las vidas no se viven de esta forma. Un individuo va repitiendo conceptos que aprendió en su niñez y suele moverse avanzando o retrociendo a través de su memoria.

En resumen, estos cuatro principios enuncian la lucha constante que se entabla entre el biógrafo y su personaje para descubrir el yo oculto y el yo revelado, el yo público y el yo privado. Y la tarea o misión principal de la narrativa biográfica es «to sort out themes and patterns, not dates and mundane calendar events which sort themselves" ${ }^{25}$. Esto puede conseguirse con los mismos recursos que han dado fuerza narrativa a la dicción: escenas y capitulos retrospectivos, resúmenes, saltos de la niñez a la madurez, visiones momentáneas del futuro, incursiones en el pasado, etc. Esta es la forma en que vivimos y nos movemos, y el arte puede derivarse de este conocimiento.

Realmente, un biógrafo que no posea un estilo literario o que carezca de concisión y claridad, debería abandonar esta tarea; vidas brillantes han

24 Ibid., pp. 28-30.

2s Ibid., p. 30. 
resultado tediosas por culpa del biógrafo y viceversa; la proporción es absolutamente necesaria, ya que se trata de moldear una vida, no de distorsionarla o someterla a su propia visión. Cuanto mejor capte el biógrafo la realidad, más real será el retrato que cree. Ha absorbido dentro de su conciencia operativa una gran cantidad de documentos acerca de la vida de otro, pero el libro que surja será su visión, su forma, su retrato, pues aunque el biógrafo oponga resistencia, pocos pueden evitar alguna forma de «transferencia» en lo más profundo de todo escrito biográfico. 